\title{
Peningkatan Kemampuan Menganalisis Siklus Air Melalui Media Puzzle Berbantuan Kartu Siklus Air Pada Siswa Kelas V SDN Besowo 2 Kecamatan Kepung Kabupaten Kediri
}

\author{
Diterima: \\ 2 April 2021 \\ Revisi: \\ 7 April 2021 \\ Terbit:
}

1 Mei 2021

\author{
Alia Nur Husna Afandi \\ Sekolah Dasar Negeri Besowo 2 \\ Kediri, Indonesia \\ E-mail: alia.pgsd@gmail.com
}

\begin{abstract}
Abstrak - Berdasarkan hasil refleksi peneliti, sebagai guru kelas V SDN Besowo 2, peneliti menemukan beberapa permasalahan pembelajaran, terutama pada proses pembelajaran sains materi menganalisis siklus air. Pada materi ini siswa cenderung kesulitan dalam memahami alur siklus air dengan baik, hal tersebut terungkap saat peneliti melakukan pre-test tanya jawab terkait konsep ini. Pada masa pandemi Covid-19, pembelajaran diarahkan pada konsep pembelajaran jarak jauh (PJJ), PJJ dapat dilakukan secara daring maupun luring. Mengingat latar belakang siswa di SDN Besowo 2 masih cukup kesulitan dalam proses pembelajaran daring, maka untuk meningkatkan kemampuan siswa dalam materi menganalisis siklus air, dirumuskan sebuah solusi yaitu menggunakan media pembelajaran puzzle berbantuan kartu siklus air. Pendekatan yang digunakan adalah penelitian kualitatif dengan desain Penelitian Tindakan Kelas (PTK), dengan tahapan yaitu 1) perencanaan, 2) pelaksanaan, 3) pengamatan, 4) refleksi. Penelitian ini direncanakan berlangsung selama 2 siklus, tiap siklus 2 pertemuan dengan materi menganalisis siklus air. Berdasarkan hasil penelitian, dapat disimpulkan bahwa, media puzzle berbantuan kartu siklus air dapat meningkatkan hasil belajar siswa pada materi siklus air. Melalui media puzzle ini, siswa dapat lebih terstimulus untuk mengeksplorasi pada kepingan-kepingan gambar yang didalamnya termuat materi pembelajaran. Melalui media puzzle, peserta didik dapat lebih aktif dalam mengikuti pembelajaran, media puzzle memiliki warna dan potongan gambar yang bervariasi sehingga lebih menarik serta akan memudahkan pengajar dalam menyampaikan isi materi.
\end{abstract}

Kata Kunci-siklus air, puzzle, kartu siklus air

Abstract - Based on the results of the researchers' reflection, as a grade V teacher at public elementary school Besowo 2, the researcher found several learning problems, especially in the process of learning science material to analyze the water cycle. In this material students tend to have difficulty understanding the flow of the water cycle properly, this was revealed when the researcher conducted a pre-test of questions and answers related to this concept. During the Covid-19 pandemic, learning was directed at the concept of distance learning, distance learning can be done online or offline. Given the background of students at public elementary school Besowo 2 still having difficulties in the online learning process, to improve students' abilities in analyzing the water cycle, a solution was formulated, namely using puzzle learning media assisted by water cycle cards. The approach used is qualitative research with a Classroom Action Research (CAR) design, with stages: 1) planning, 2) implementation, 3 ) observation, 4) reflection. This research is planned to last for 2 cycles, each cycle 2 meetings with material to analyze the water cycle. Based on the research results, it can be concluded that, puzzle media assisted with water cycle cards can improve student learning outcomes in the water cycle material. Through this puzzle media, students can be more stimulated to explore the pieces of images which contain learning material. Through puzzle media, students can be more active in participating in learning, puzzle media has varied colors and pieces of images so that it is more interesting and will make it easier for teachers to convey the content of the material.

Keywords-water cycle, puzzle, water cycle card 
PTK, Vol.1 No.2 Mei 2021

ISSN: 2747-1977 (Print) / 2747-1969 (Online)

Website: https://jurnal.ciptamediaharmoni.id/index.php/ptk/

\section{PENDAHULUAN}

Dalam kaitannya faktor kegiatan pembelajaran, proses pembelajaran Sains mutlak terjadi pada Kurikulum 2013 (Akbar, 2013). Proses mempelajari Sains dengan benar akan melatih siswa menggunakan prinsip-prinsip logika dalam mengevaluasi apakah informasi yang diperoleh itu benar atau salah. Proses ini akan mengasah ketajaman siswa dalam berpikir kritis dan menggunakan logika (Subekti, 2012). Kemudian menurut Destya (2014), Sains sangat mendukung kemajuan suatu bangsa. Sains merupakan dasar teknologi yang merupakan tulang punggung pembangunan. Selain itu, Sains mampu mengembangkan sikap ilmiah yang membentuk insan Indonesia berkepribadian luhur. Nilai-nilai pendidikan tercermin pada sikap ilmiah yang mulai muncul saat pembelajaran yang ditandai dengan munculnya rasa keingintahuan.

Berdasarkan hasil refleksi peneliti, sebagai guru kelas V SDN Besowo 2, peneliti menemukan beberapa permasalahan pembelajaran, terutama pada proses pembelajaran sains materi menganalisis siklus air. Pada materi ini siswa cenderung kesulitan dalam memahami alur siklus air dengan baik, hal tersebut terungkap saat peneliti melakukan pre-test tanya jawab terkait konsep ini.

Siklus air adalah sebuah proses siklus yang terjadi secara terus menerus dan tidak pernah berhenti atau bahkan habis mulai dari air yang ada di daratan berubah menjadi awan kemudian menjadi hujan. Terjadi 3 tahapan proses dalam siklus air yang berjalan secara sistematis dan beraturan yakni evaporasi, kondensasi, dan presipitasi. Di samping itu terdapat 2 tahapan yang tidak masuk dalam tahapan siklus air di kelas 5, namun tahapan ini berpengaruh terhadap siklus air yaitu transpirasi dan infiltrasi.

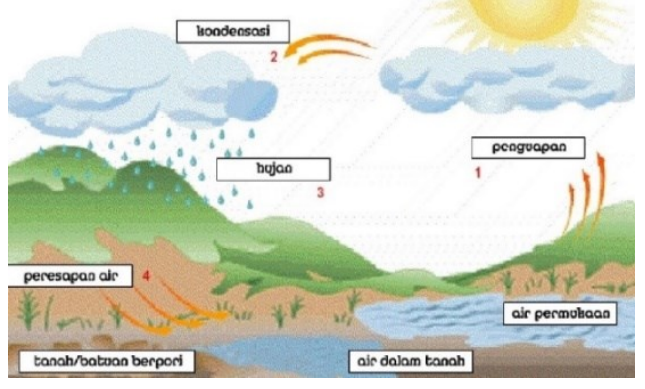

Gambar 1. Siklus Air 
Website: https://jurnal.ciptamediaharmoni.id/index.php/ptk/

Proses identifikasi masalah untuk menemukan penyebab permasahan di atas telah dilakukan dan disimpulkan bahwa beberapa penyebabnya antara lain adalah, sebagian besar siswa masih belum mampu secara maksimal mengabstraksi materi pengantar tentang siklus air yang disampaikan oleh peneliti dan pada proses pembelajaran masih belum menggunakan media yang dapat menjelakan secara visual dengan baik materi tersebut.

Pada masa pandemi Covid-19, pembelajaran diarahkan pada konsep pembelajaran jarak jauh (PJJ), PJJ dapat dilakukan secara daring maupun luring. Mengingat latar belakang siswa di SDN Besowo 2 masih cukup kesulitan dalam proses pembelajaran daring, maka untuk meningkatkan kemampuan siswa dalam materi menganalisis siklus air, dirumuskan sebuah solusi yaitu menggunakan media pembelajaran. Peran media sangat penting dalam proses pembelajaran agar informasi yang disampaikan guru tidak bersifat verbal dan mudah diterima. Kehadiran media pembelajaran dapat mempermudah siswa dalam memahami materi ajar walaupun melintasi berbagai ruang dan waktu. Selain itu, media dapat meningkatkan atensi siswa, dimana salah satu tujuan media adalah untuk menarik dan mengarahkan perhatian siswa berkonsentrasi kepada isi pelajaran (Arsyad, 2013).

Kemudian menurut Sudjana \& Rivai (2015), menyebutkan bahwa media pembelajaran dalam proses belajar bermanfaat agar: (a) pembelajaran lebih menarik perhatian sehingga menumbuhkan motivasi belajar siswa, (b) materi pembelajaran akan lebih mudah dipahami oleh siswa, (c) metode mengajar menjadi lebih variatif sehingga dapat mengurangi kebosanan belajar, (d) siswa lebih aktif melakukan kegiatan belajar. Sedangkan Arif S. Sadiman, dkk. (2006) menjelaskan kegunaan media pembelajaran sebagai berikut: (a) memperjelas penyajian pesan, (b) mengatasi keterbatasan ruang, waktu, dan daya indera, (c) mengatasi sikap pasif, sehingga peserta didik menjadi lebih semangat dan lebih mandiri dalam belajar, (d) memberikan rangsangan, pengalaman, dan persepsi yang sama terhadap materi belajar.

Dari hal di atas, media yang difokuskan untuk dijadikan solusi adalah media puzzle, berdasarkan jenisnya, media puzzle termasuk ke dalam jenis media visual yaitu media grafis. Menurut Sudjana \& Rivai (2015), media grafis dapat didefinisikan sebagai media yang mengombinasikan fakta dan gagasan secara jelas, kuat, dan terpadu, melalui kombinasi pengungkapan kata-kata dan gambar. Media puzzle termasuk media grafis, karena media puzzle menggabungkan unsur-unsur kata-kata dengan gambar, sehingga media puzzle dapat menjelaskan sebuah gambaran suatu konsep sesuai dengan kenyataan yang ada.

Untuk memaksimalkan peran puzzle dalam konsep pembelajaran siklus air, maka diperbantukan dengan media kartu siklus air, yaitu media kartu yang berisi gambar konsep proses siklus air dan kartu yang berisi deskripsi dari konsep proses siklus air. Konsep kartu ini mengambil prinsip model make a match. Suyatno (2009) mengungkapkan bahwa model make a 
PTK, Vol.1 No.2 Mei 2021

ISSN: 2747-1977 (Print) / 2747-1969 (Online)

Website: https://jurnal.ciptamediaharmoni.id/index.php/ptk/

match adalah model pembelajaran dimana guru menyiapkan kartu yang berisi soal atau permasalahan dan menyiapkan kartu jawaban kemudian siswa mencari pasangan kartunya. Menggunakan kartu pintar ini diharapkan dapat melatih kecepatan berfikir siswa.

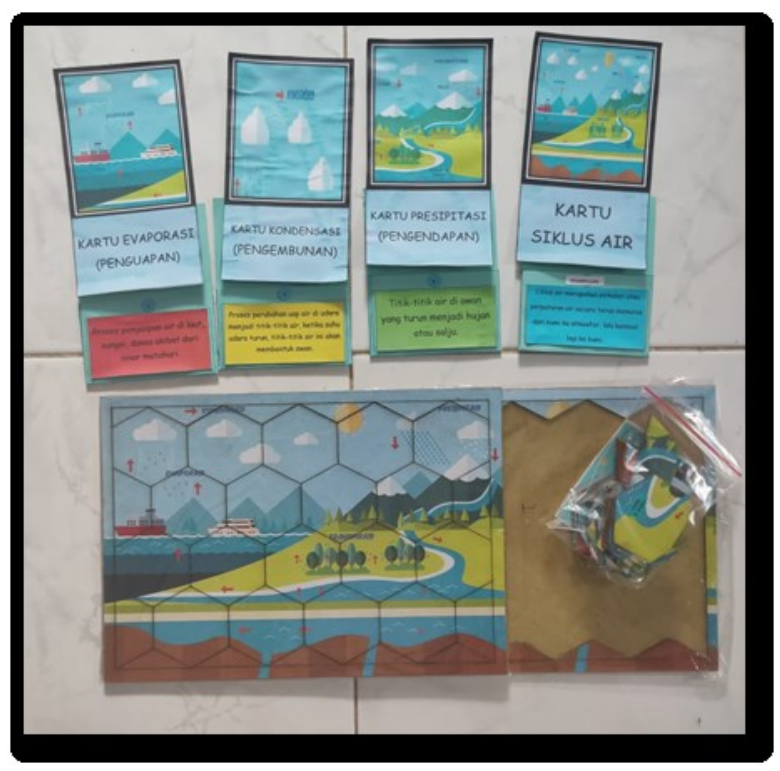

Gambar 2. Media Puzzle dan kartu siklus air

Berdasarkan pertimbangan di atas, peneliti menyusun sebuah penelitian tindakan kelas dengan judul "Peningkatan Kemampuan Menganalisis Siklus Air Melalui Media Puzzle berbantuan Kartu Siklus Air pada Siswa Kelas V SDN Besowo 2 Kecamatan Kepung Kabupaten Kediri”. Berdasarkan judul tersebut dirumuskan tujuan penelitian tindakan ini adalah untuk menjelaskan peningkatan kemampuan menganalisis Siklus Air melalui media Puzzle berbantuan Kartu Siklus Air pada siswa kelas V SDN Besowo 2 Kecamatan Kepung Kabupaten Kediri.

\section{METODE}

\subsection{Pendekatan Penelitian}

Pendekatan yang digunakan adalah penelitian kualitatif dengan desain Penelitian Tindakan Kelas (PTK), dengan tahapan yaitu 1) perencanaan, 2) pelaksanaan, 3) pengamatan, 4) refleksi (Arikunto, 2010:16). Penelitian ini direncanakan berlangsung selama 2 siklus, tiap siklus 2 pertemuan dengan materi menganalisis siklus air. Secara keseluruhan, tindakan kelas pada materi siklus air ini terdiri dari empat pertemuan, dua pertemuan pada siklus pertama, dan dua pertemuan pada siklus kedua. Merurutan materi pembelajaran pada empat pertemuan tersebut antara lain: (1) pengertian siklus air dan macam-macamnya, (2) tahapan siklus air dan contoh masing-masing macamnya, (3) faktor yang memengaruhi dan fungsi masing-masing macamnya, 
(4) manfaat masing-masing macamnya bagi kehidupan manusia dan peran manusia untuk menjaga keberlangsungan siklus air.

Adapun alur siklus PTK akan digambarkan seperti di bawah ini.

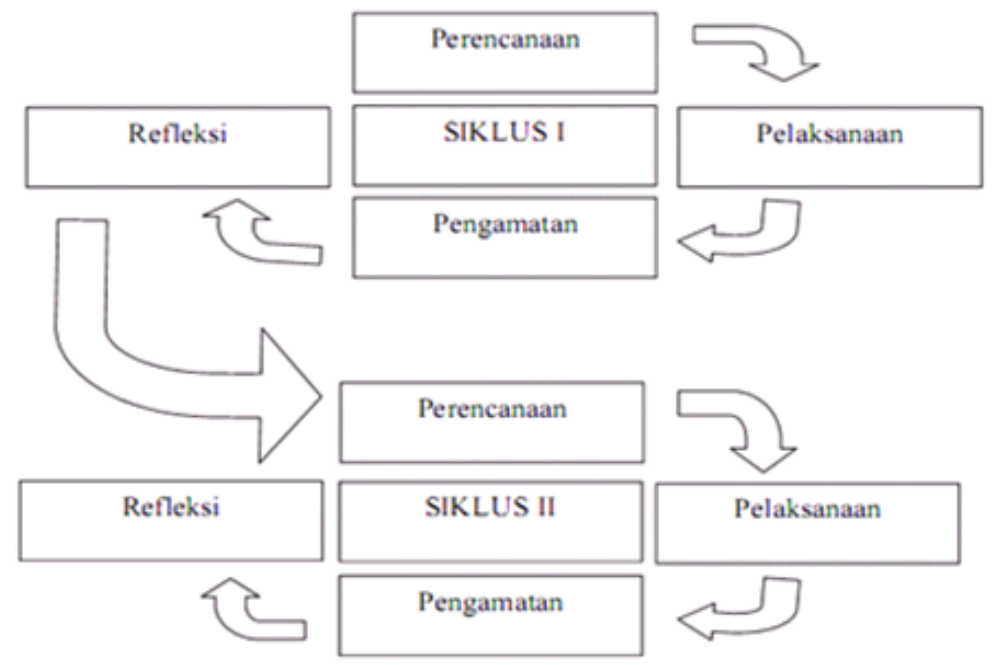

Gambar 3. Siklus PTK

Siklus I, Siklus ini terdiri dari empat tahap yaitu perencanaan, pelaksanaan, pengamatan dan refleksi. Berikut penjelasan masing-masing tahapannya. Perencanaan, langkah-langkah ini terdiri dari pengembangan RPP, penyiapan media pembelajaran Puzzle berbantuan kartu siklus air, LKPD, soal evaluasi, dan lembar observasi pelaksanaan pembelajaran. Pelaksanaan, pada tahap ini peneliti melaksanakan pembelajaran pada materi Siklus Air melalui media Puzzle berbantuan kartu siklus air. Observasi, tahap ini dilakukan pada saat pembelajaran jarak jauh dilakukan oleh siswa, peneliti sebagai guru melakukan observasi jarak jauh proses pengerjaan lembar kerja oleh siswa melalui foto-foto saat siswa belajar dari rumah. Refleksi, pada tahap ini peneliti mengkaji ulang pembelajaran yang telah dilaksanakan, apa yang sudah dan belum tercapai, masalah-masalah apa saja yang muncul, dan menyiapkan berbagai alternatif pemecahan masalah agar pada siklus berikutnya lebih maksimal.

Siklus II, Siklus ini memiliki tahapan yang sama dengan siklus I yaitu perencanaan, pelaksanaan, observasi dan refleksi. Apa yang belum tercapai dalam siklus I bisa diteruskan pada siklus II ini. Kegitan pada siklus ini menyesuaikan dengan permasalahan pembelajaran pada siklus I. Setelah siklus II berakhir maka penelitian ini dihentikan.

\subsection{Subjek Penelitian}

Subjek yang diteliti pada penelitian ini adalah siswa kelas V semester genap tahun ajaran 2019/2020 di SDN Besowo 2 Kecamatan Kepung Kabupaten Kediri dengan jumlah siswa sebanyak 11 siswa. 
PTK, Vol.1 No.2 Mei 2021

ISSN: 2747-1977 (Print) / 2747-1969 (Online)

Website: https://jurnal.ciptamediaharmoni.id/index.php/ptk/

\subsection{Waktu Pelaksanaan}

Waktu penelitian ini dilaksanakan mulai tanggal 13 Maret 2020 sampai tanggal 13 April 2020 semester genap tahun pelajaran 2019/2020.

\subsection{Data dan Instrumen Penelitian}

Data pada penelitian ini adalah data berupa ketercapaian pembelajaran jarak jauh menggunakan media Puzzle berbantuan kartu siklus air menggunakan instrument lembar observasi dan data hasil belajar siswa pada materi menganalisis siklus air. Data ketercapaian pembelajaran merupakan data kualitatif berupa catatan-catatan guru terhadap kekuatan dan kelemahan proses pembelajaran, sedangkan data hasil belajar merupakan data kuantitatif yang akan diambil sebanyak empat kali selama dua siklus (dua kali pada masing-masing siklus).

Data hasil belajar diambil dari soal evaluasi, soal ini dikembangkan menjadi lima soal pilihan ganda dan tujuh soal jawaban singkat, kriteria ketuntasan minimal (KKM) pengerjaan soal ini adalah mendapatkan skor $75 \%$.

\subsection{Teknik Analisis Data}

Analisis data pada penelitian ini menggunakan teknik kualitatif dan kuantitatif. Untuk data kualitatif adalah data ketercapaian pembelajaran, yaitu data kekuatan dan kelemahan pembelajaran di bahas, direfleksikan, dan di rumuskan simpulannya. Untuk data deskriptif kuantitatif adalah data angka hasil belajar siswa, dibandingkan dengan KKM, dianalisis, dan dimaknai secara deskriptif.

\section{HASIL DAN PEMBAHASAN}

\subsection{Hasil Ketercapaian Pembelajaran}

Pembelajaran jarak jauh materi siklus air menggunakan media puzzle berbantuan kartu siklus air diawali dengan memanggil siswa satu persatu kesekolah dengan jadwal yang berbeda dan dengan protokol kesehatan yang ketat untuk mengambil (1) lembar kerja peserta didik (LKPD), (2) media puzzle, dan (3) media kartu siklus air. Kemudian, siswa diminta untuk mengerjakannya di rumah masing-masing.

Pada saat mengerjakan puzzle dengan benar, dipastikan akan terjadi proses kognitif yang tinggi saat melakukan pencermatan pada masing-masing keeping puzzle, selain itu, terlihat dari dokumentasi kegiatan, siswa menunjukkan ciri-ciri keberminatan yang baik dalam menyelesaikan tantangan media puzzle ini, siswa merasa sedang bermain, namun sebetulnya ada proses belajar di sana.

Hal di atas, diharapkan dapat meningkatkan memori siswa dalam menghafal siklus air dengan benar. Sesuai dengan yang disampaikan oleh Lukitaningsih (2015), bahwa (1) 
PTK, Vol.1 No.2 Mei 2021

ISSN: 2747-1977 (Print) / 2747-1969 (Online)

Website: https://jurnal.ciptamediaharmoni.id/index.php/ptk/

permainan puzzle dapat menarik minat belajar siswa, (2) gambar pada puzzle dapat mengatasi keterbatasan ruang dan waktu, (3) dengan adanya media pembelajaran siswa dapat melihat, mengamati dan melakukan percobaan serta dapat menambah wawasan.

Setelah siswa menyelesaikan media puzzle, maka tahap berikutnya adalah siswa mengerjakan lembar kerja peserta didik (LKPD) berdasarkan media kartu siklus air yang berisi materi-materi. Melaui media-media yang menarik, membuat siswa lebih antusias dalam mengerjakan LKPD.

3.2 Data Hasil Belajar Siswa pada Materi Kemampuan Menganalisis Siklus Air

Tabel 1. Hasil Belajar Siswa pada Materi Kemampuan Menganalisis Siklus Air

\begin{tabular}{|c|c|c|c|c|c|}
\hline \multirow{2}{*}{ No } & \multirow{2}{*}{ Nama (Inisial) } & \multicolumn{2}{|c|}{ Skor Evaluasi Siklus 1} & \multicolumn{2}{|c|}{ Skor Evaluasi Siklus 2} \\
\hline & & $\begin{array}{c}\text { Pertemuan } \\
1 \\
\end{array}$ & $\begin{array}{c}\text { Pertemuan } \\
2 \\
\end{array}$ & $\begin{array}{c}\text { Pertemuan } \\
1 \\
\end{array}$ & $\begin{array}{c}\text { Pertemuan } \\
2 \\
\end{array}$ \\
\hline 1 & APR & 33 & 58 & 64 & 67 \\
\hline 2 & AP & 73 & 75 & 81 & 100 \\
\hline 3 & BBB & 47 & 74 & 80 & 93 \\
\hline 4 & CADM & 40 & 60 & 74 & 87 \\
\hline 5 & $\mathrm{DB}$ & 53 & 74 & 80 & 100 \\
\hline 6 & DDL & 40 & 65 & 74 & 93 \\
\hline 7 & JDH & 53 & 74 & 80 & 87 \\
\hline 8 & LEN & 73 & 80 & 86 & 100 \\
\hline 9 & $\mathrm{OP}$ & 40 & 65 & 71 & 73 \\
\hline 10 & RES & 60 & 80 & 85 & 93 \\
\hline \multirow[t]{2}{*}{11} & $\mathrm{~S}$ & 67 & 80 & 85 & 100 \\
\hline & JUMLAH & 579 & 785 & 860 & 993 \\
\hline & RATA-RATA & 53 & 71.36 & 78.18 & 90 \\
\hline \multicolumn{2}{|r|}{ PERSENTASE } & & & & \\
\hline & $\begin{array}{l}\text { ETUNTASAN } \\
\text { KKM } \\
\end{array}$ & $0 \%$ & $36 \%$ & $64 \%$ & $82 \%$ \\
\hline
\end{tabular}


PTK, Vol.1 No.2 Mei 2021

ISSN: 2747-1977 (Print) / 2747-1969 (Online)

Website: https://jurnal.ciptamediaharmoni.id/index.php/ptk/

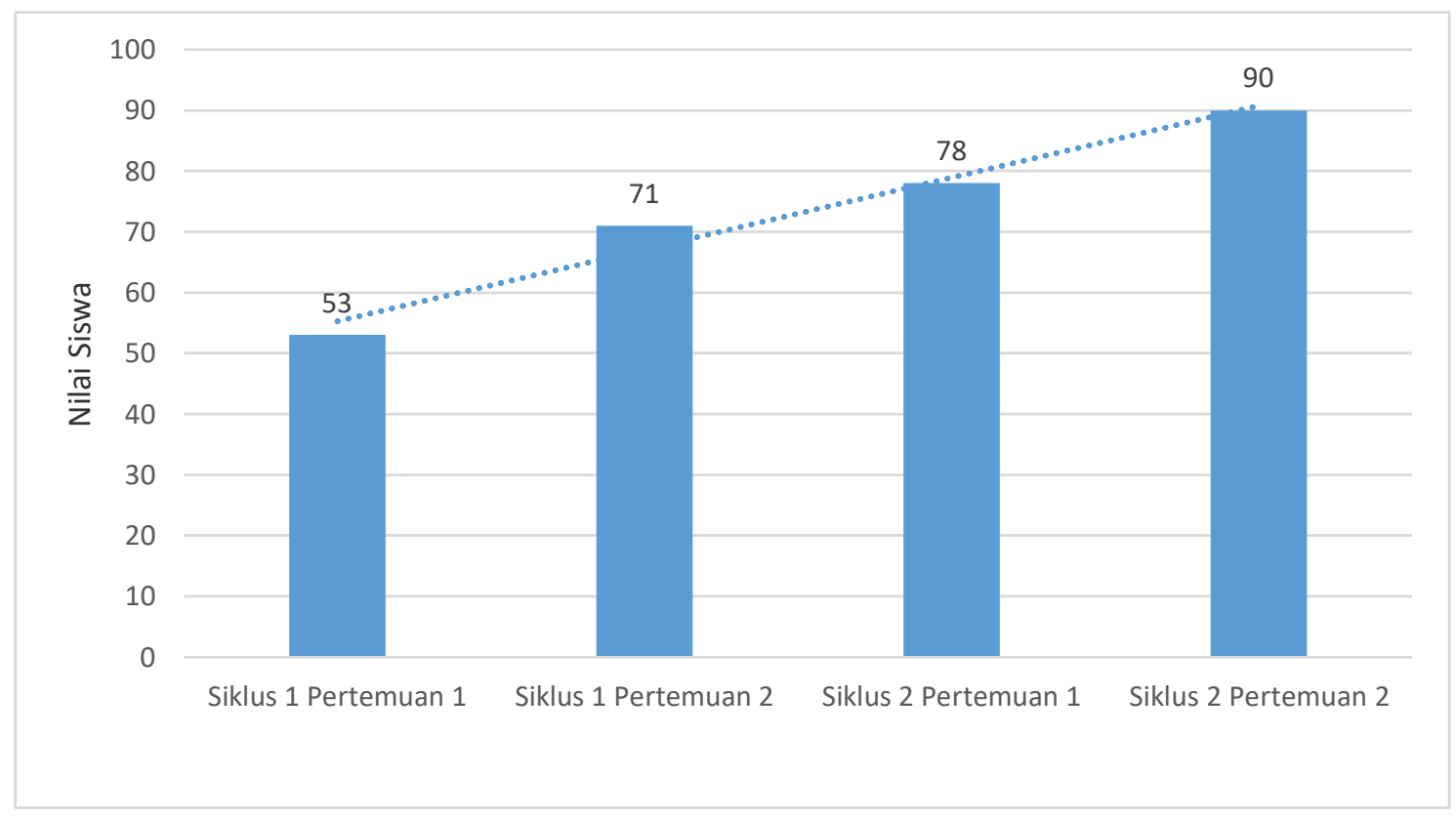

Gambar 4. Grafik Hasil Belajar Siswa

Dari hasil grafik di atas dapat diamati bahwa, hasil belajar siswa mengalami peningkatan pada tiap pertemuannya. Pada pertemuan pertama materi pengertian siklus air dan macammacamnya, siswa masih agak kesulitan, terutama terhadap pengertian macam-macam siklus air, seperti evaporasi, kondensasi, dan resipitasi, hal tersebut diketahui dari rata-rata hasil belajar siswa hanya memeroleh nilai 53. Pada pertemuan ke-2, penggunaan media pembelajaran mulai membuahkan hasil, pada materi tahapan siklus air dan contoh masing-masing macamnya, ratarata hasil belajar siswa mengalami peingkatan sebesar 18 poin, menjadi 71. Pada pertemuan ke3 , materi faktor yang memengaruhi dan fungsi masing-masing macamnya, kembali mengalami peningkatan sebesar 7 poin, menjadi 78. Terakhir pada pertemuan ke-4, materi manfaat masingmasing macamnya bagi kehidupan manusia dan peran manusia untuk menjaga keberlangsungan siklus air mendapatkan rata-rata hasil belajar 90, dengan persentase ketuntasan KKM 82\%.

Keefektifan media puzzle menjadi faktor penyebab peningkatan hasil belajar ini. Melalui media puzzle, siswa menjadi lebih tertarik belajar, dan dapat mengkonkritkan siklus air dengan baik. Seperti pendapat Kuriniawati (2014) Media Puzzle merupakan salah satu media pembelajaran yang dapat menarik perhatian siswa, dimana media tersebut merupakan jenis permainan dengan merangkai potongan-potongan gambar maupun benda menjadi gambar atau benda tiga dimensi yang utuh sehingga akan membuat proses berfikir siswa menjadi lebih kreatif. Melalui media puzzle ini, siswa dapat lebih terstimulus untuk mengeksplorasi pada kepingan-kepingan gambar yang didalamnya termuat materi pembelajaran. Melalui media puzzle, peserta didik dapat lebih aktif dalam mengikuti pembelajaran, media puzzle memiliki 
warna dan potongan gambar yang bervariasi sehingga lebih menarik serta akan memudahkan pengajar dalam menyampaikan isi materi (Bahar dan Risnawati, 2019).

\section{KESIMPULAN}

Berdasarkan hasil dan pembahasan di atas, dapat disimpulkan bahwa, media puzzle berbantuan kartu siklus air dapat meningkatkan hasil belajar siswa pada materi siklus air. Melalui media puzzle ini, siswa dapat lebih terstimulus untuk mengeksplorasi pada kepingan-kepingan gambar yang didalamnya termuat materi pembelajaran. Melalui media puzzle, peserta didik dapat lebih aktif dalam mengikuti pembelajaran, media puzzle memiliki warna dan potongan gambar yang bervariasi sehingga lebih menarik serta akan memudahkan pengajar dalam menyampaikan isi materi.

\section{DAFTAR PUSTAKA}

Akbar, S. 2013. Implementasi Pembelajaran Tematik Terpadu Berorientasi pada Pendidikan Karakter. Malang: Handout.

Arief S Sadiman, dkk. 2006. Media Pendidikan. Jakarta: PT Raja Grafindo Persada.

Arikunto, Suharsimi. dkk. 2010. Penelitian Tindakan Kelas. Jakarta: Bumi Aksara.

Arsyad, A. 2013. Media Pembelajaran. Jakarta: PT. Raja Grafindo Persada.

Bahar \& Risnawati, Pengaruh Penggunaan Media Puzzle Terhadap Hasil Belajar Matematika Siswa Kelas III SD di Kabupaten Gowa, Jurnal Publikasi Pendidikan, 2019: 9(1): 77-86.

Desstya, A. (2014). Kedudukan dan aplikasi pendidikan sains di sekolah dasar.

Kurniawati, I., Enni Suwarsi Rahayu, Pengembangan Media "Woody Puzzle" Untuk Meningkatkan Motivasi, Aktivitas Dan Hasil Belajar Siswa Materi Struktur Jaringan Tumbuhan, Unnes Journal of Biology Education, 2014: 3 (3) : 291-296.

Lukitaningsih, T. 2015. Peningkatan pencapaian kompetensi siswa kelas VIII G SMP

Negeri 2 Paron pada materi sistem pencernaan manusia dengan pendekatan saintifik melalui media puzzle. Jurnal Florea, 2 (1 ):5-12.

Subekti, W. 2012. Pentingnya Sains dalam Pendidikan, (Online), (https://www.zenius.net/blog/139/manfaat-belajar-sains), diakses pada 8 Maret 2020. 
PTK, Vol.1 No.2 Mei 2021

ISSN: 2747-1977 (Print) / 2747-1969 (Online)

Website: https://jurnal.ciptamediaharmoni.id/index.php/ptk/

Sudjana, N, \& Rivai, A (2015). Media Pengajaran. Cetakan ke-12. Bandung: Sinar. Baru Algensindo

Suyatno. 2009. Menjelajah Pembelajaran Inovatif. Masmedia Buana Pustaka: Sidoarjo. 